\title{
Semblanza de un gran amigo: el Dr. Ing. Óscar Penny Cabrera
}

Héctor Gustavo Roselló Moreno*

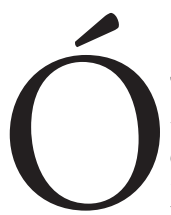

scar Penny Cabrera fue un contralmirante de la Marina de Guerra del Perú en retiro, esposo y padre de dos hijos. Era doctor en Ingeniería, graduado de la Universidad de Pisa, Italia. Gran investigador y maestro dentro y fuera del aula, es recordado, por todos aquellos que fueron sus alumnos y amigos, como un ser humano y un profesional excepcional ${ }^{1}$.

Al inicio de los años 90, trabajábamos en el primer programa de maestría en telecomunicaciones entre INICTEL y URP. Óscar se contactó con INICTEL para coordinar un proyecto que estaba realizando: una fuente de alimentación para botes. INICTEL, conocedor del currículo de él, le ofre-

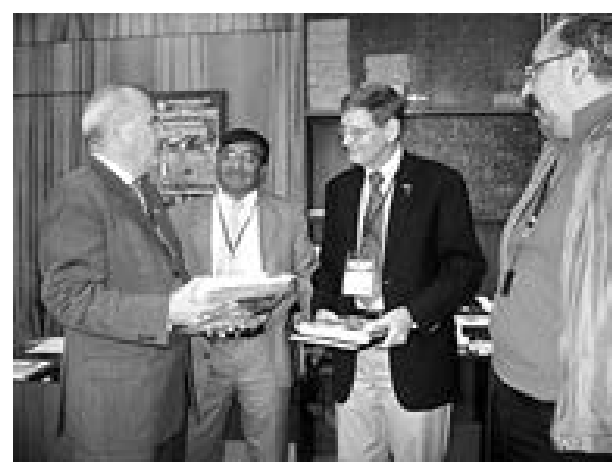

El Dr. Ing. Óscar Penny en octubre del 2011 durante la inspección in-situ de equipo de evaluadores internacionales de ABET. ce inmediatamente un contrato para enseñar en la maestría, oportunidad que no desperdició, pues buscaba difundir sus conocimientos en un nivel académico avanzado. Fue a partir de ese momento que comenzamos a trabajar juntos, lo que desencadenó naturalmente en el desarrollo de nuestra amistad. Para quienes lo conocieron, aquello no es extraño, ya que el carácter de Óscar permitía congeniar muy rápidamente. Siempre fue una persona muy afable y dispuesta a apoyar a quien se lo pidiera. Conversábamos mucho de temas académicos. De vez en cuando, nos reuníamos con un grupo de colegas para departir socialmente, pero siempre terminábamos hablando del trabajo que nos apasionaba.

Óscar nació un 2 de marzo de 1950. En la época de su juventud, según nos contaba, era inquieto, lo cual lo condujo a realizar estudios en el colegio Champagnat, en el San Vicente (Ica) y en el Santa Rosa (Maryknoll). Un día se decidió a ingresar a la Escuela de la Marina del Perú y lo logró el 27 de febrero de 1968, donde estudió dos años. Empezó a destacar sobre sus compañeros. Eso le permitió conseguir trasladarse a la Academia Naval en Livorno, Italia, por 4 años más. Muchas de las experiencias que nos contaría en los momentos de tertulia entre momentos de trabajo las vivió ahí. De uno de esos momentos es que recuerdo una anécdota que a todos nos permitió aprender y nos sorprendió, porque se enfrentaba a lo que todos conocíamos como la historia del Perú. Nos contó que una vez, en el aula, uno de sus profesores, sabiendo que él era de Perú, le preguntó por qué el salitre fue el motivo principal de la Guerra del Pacifico. Óscar le respondió algo que sabíamos todos, que era muy útil como abono. El profesor le contestó: "O sea que ahora las guerras se libran por satisfacer el hambre del mundo... ¡Vaya a la biblioteca y no regrese hasta que sepa la respuesta!". Óscar nos explicó que así lo hizo. Gracias a que la escuela de Livorno es una de las tantas en Europa que tiene mucha documentación

\footnotetext{
* Docente de la Facultad de Ingeniería, Universidad Ricardo Palma. hector.rosellom@urp.pe

1 Periódico PROPUESTA No102 Octubre 2015 Edición Universidad Ricardo Palma.
} 
sobre la historia de las guerras, con análisis de los pormenores realizados por investigadores de historia militar, encontró que el salitre contenía el nitrógeno y que ese era un componente importante para desarrollar la pólvora. En esa época, a fines del siglo XVIII, los yacimientos de caliche que explotaban en la India, que no eran de mayor cuantía, rápidamente comenzaron a agotarse, lo que condujo a paralizar la creciente sociedad industrial que tenía Inglaterra. Eso la obligó a buscar otra fuente grande de salitre, que encontró en Sudamérica. En esa época, la pelea por la hegemonía del mundo era entre los grandes imperios de Europa, de los cuales Inglaterra formaba parte. Los yacimientos de salitre de Perú y Bolivia aseguraban al país sajón el aprovisionamiento de pólvora y continuidad de su industria química. Allí, aprendió muchas lecciones de una marina que participó en acciones de guerra y que podía enseńar mucho a la nuestra. Por ello, trató de aplicar esas lecciones cuando regresó.

Al terminar la academia, cursó estudios en la Universidad de Pisa, donde obtuvo su licenciatura y, después, la Laurea de Doctor en Ingeniería Electrónica, luego de presentar su tesis Investigación de filtros digitales para radares. Fue asesorado por su profesor, el Dr. Umberto Mengali, quien fuera alumno de Ugo Tiberio, quien, a su vez, fue alumno ${ }^{2}$ de Guglielmo Marconi. Es decir, no solo venía de una escuela especialista en investigación y desarrollo de tecnología de radares, sino que era uno de sus dignos representantes. Eso se debió a que se había graduado con altos honores de esa escuela, lo cual representó, luego, una valiosa oportunidad que la escuela de electrónica, así como la Marina peruana, tuvo al contar con él durante varios ańos.

Otro de los tantos conocimientos que él compartía con nosotros era la lección que aprendió Italia luego de los trágicos sucesos de la batalla de Gaudo, o cabo Matapán, sufridos por la Marina de ese país. A partir de ese momento histórico, se debía tener presente lo que ocurre cuando se abandona el desarrollo de la tecnología en un país por no darle la importancia debida. Además, Óscar realizó una capacitación STC VM8/61 Kiel en Alemania, lo que le permitió aplicar sus conocimientos y aportar en el desarrollo del filtro que mejoró significativamente: el alcance del radar que se desarrollaba en esa oportunidad.

Al regresar al país, luego de un proceso de sustentación de tesis y revalidación académica en la UNI, obtuvo el título de Ingeniero Electrónico. Asimismo, realizó un diplomado en Relaciones Internacionales en la Pontificia Universidad Católica del Perú y una licenciatura en Ciencias Marítimas y Navales en la Escuela Naval del Perú. Ascendió a contralmirante el 1 de enero de 1999. Se puede decir que nunca dejaba de estudiar. Conocía varios idiomas: hablaba el francés y el alemán, y dominaba el inglés y el italiano.

Óscar se caracterizó por ser un reconocido académico que, además, aplicaba el conocimiento. Es decir, no se limitó a las labores teóricas sino que desarrolló varios proyectos vinculados, principalmente, a los radares, que eran su especialidad. Participó en el diseño de equipos nuevos en Holanda y Alemania, donde creó un algoritmo para la mejora de las comunicaciones. Cuando este fue aplicado, le hizo ganar respeto en la comunidad científica internacional. Asimismo, realizó muchas mejoras en los sistemas de radares de la Marina de Guerra. Eso trajo como consecuencia el desarrollo de tecnología propia y ahorró millones de dólares a la institución y, por ende, al país.

Desde 1993 hasta junio del 2014, fue docente de la Universidad Ricardo Palma, en la escuela académico profesional de Ingeniería Electrónica, dictando el curso de Control y Procesamiento Digital de Señales. A su vez, fue profesor de dos cursos de sistemas: Comunicación por Fibras Ópticas y Procesamiento Digital de señales, ambos inscritos en el Programa de Maestrías de Ingeniería de Telecomunicaciones de la URP y en el Instituto Nacional de Telecomunicaciones (INICTEL) desde 1990.

2 Falciasecca Gabriele, Barbara Valott "Guglielmo Marconi: Tra Storia E Cronaca”, [Pontecchio Marconi, Italy]: Fondazione Guglielmo Marconi ; [Bologna, Italy] pendragon 2006. 
Fue uno de los directores del SIMA, a la cual salvó de una crisis económica logrando un contrato con la industria privada para fabricar una serie de naves que pusieron en azul al SIMA. Fue agregado naval de la Organización Marítima Internacional (OMI) en Londres entre los años 2006 y 2007. De esta manera, realzó la labor del especialista peruano, debido a sus conocimientos de electrónica y marina, y gracias a su amplia capacidad de trabajo. En consecuencia, logró el reconocimiento de sus pares.

Ya en retiro, se le nombró director de la escuela académico profesional de Ingeniería Electrónica. Desde abril del 2008 hasta junio del 2014, fue el responsable del proceso de acreditación internacional de la escuela de Ingeniería de la URP ante la Accreditation Board of Engineering and Technology (ABET) y ante el Instituto de Calidad y Acreditación de Programas de Computación, Ingeniería y Tecnología (ICACIT). Así, afianzó a la escuela en su camino a la excelencia. Fue presidente del Instituto de Ingenieros Eléctricos y Electrónicos, Sección IEEE-PERU, entre los años 2011 y 2012.

Donde fuese que nos representó, siempre dejó en alto el nombre del Perú, y representó la mejor imagen y capacidad que se puede tener de un ingeniero peruano.

Entre muchos de sus intereses se encontraba la creación de drones, en la que involucraba activamente a los alumnos. Sin embargo, no se limitaba a la compra de partes para que sean ensambladas ni a la instalación de programas bajados de internet. Él siempre motivó a los estudiantes a crear tecnología propia desde el inicio. Sus investigaciones se centraban en la estabilidad de los drones por medio del desarrollo de algoritmos específicos para mejorar en este aspecto, ya que es uno de los mayores problemas de estos artefactos. Era un profundo matemático y colaboró mucho en la universidad, en el área de Control y Automatización Electrónica. En una oportunidad, fue tentado para dictar cátedra en Inglaterra, pero primaron su amor por el Perú y la tarea que se había trazado de contribuir con la educación de los futuros ingenieros.

Óscar fue, además, un nexo importante entre la Marina (específicamente el SIMA) y la Universidad Ricardo Palma. Consiguió que muchos alumnos hicieran sus prácticas y trabajaran el área de desarrollo electrónico de esta institución implementando mejoras en la microelectrónica con FPGA, reduciendo el tamaño de las tarjetas, actualizando la tecnología y modernizando a bajo costo las naves. Para lograrlo, puso en juego su futuro en la Marina, pues, de salir mal, le costaría su ascenso. Pero, como buen visionario, no fue defraudado por el personal con el que desarrolló el proyecto y tuvo éxito como en muchas de las empresas en que se embarcaba.

No se debe olvidar que fue promotor y organizador de los concursos de innovaciones electrónicas para escolares. Además, quiso crear una escuela de radares en el Perú e implementar un sistema de becas para alumnos sobresalientes con pocos recursos. Era un convencido de la necesidad de desarrollar una tecnología propia en el país para estar a la vanguardia en la región. Es una lástima que aquellos que tienen el poder económico no posean la visión para invertir en el futuro tecnológico, que es lo único que, hasta ahora, tiene un gran valor agregado, ya que se requiere poca materia prima y presenta alta diversificación en sus productos. Solo basta observar el caso de Corea al respecto. Asimismo, Óscar fue un apasionado de la Historia. Siempre que nos reuníamos, acabábamos escuchando cómo hablaba de ella cual erudito. Tenía la convicción de que servía para entender y analizar correctamente el pasado, única forma de poder crear un futuro mejor. 